\title{
Article
}

\section{Why make the effort? Exploring Recovery College Engagement}

Harper, Leanne and Mckeown, Michael

Available at http://clok.uclan.ac.uk/21062/

Harper, Leanne and Mckeown, Michael ORCID: 0000-0003-0235-1923 (2018) Why make the effort? Exploring Recovery College Engagement. Mental Health and Social Inclusion, 22 (1). pp. 27-33. ISSN 2042-8308

It is advisable to refer to the publisher's version if you intend to cite from the work. https://doi.org/10.1108/MHSI-10-2017-0043

For more information about UCLan's research in this area go to

http://www.uclan.ac.uk/researchgroups/ and search for < name of research Group>.

For information about Research generally at UCLan please go to http://www.uclan.ac.uk/research/

All outputs in CLoK are protected by Intellectual Property Rights law, including Copyright law. Copyright, IPR and Moral Rights for the works on this site are retained by the individual authors and/or other copyright owners. Terms and conditions for use of this material are defined in the policies page.

\section{CLoK}

Central Lancashire online Knowledge www.clok.uclan.ac.uk

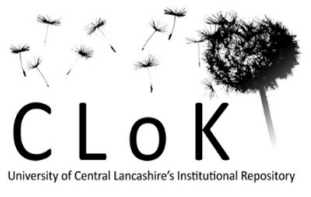




\section{Why make the effort? Exploring Recovery College Engagement}

\begin{tabular}{|r|l|}
\hline Journal: & Mental Health and Social Inclusion \\
\hline Manuscript ID & MHSI-10-2017-0043 \\
\hline Manuscript Type: & Primary Research Paper \\
\hline Keywords: & Mental Health, Recovery, Recovery College, Co-production \\
\hline \multicolumn{2}{|l}{} \\
\end{tabular}

\section{SCHOLARONE"}

Manuscripts 


\title{
Why make the effort? Exploring Recovery College Engagement
}

\begin{abstract}
Purpose - Whilst there is growing evidence to suggest that the Recovery College (RC) environment supports students towards their mental health recovery (Meddings et al., 2015b), students' initial motivations for engagement, alongside factors that may hinder or support attendance, have yet to be exclusively explored.
\end{abstract}

Design - All new RC students were invited to take part in a semi-structured interview three months following their enrolment. Four participants completed an interview which were later analysed using Thematic Analysis.

Findings - Four themes emerged within analysis: Making the effort; Being "too unwell"; Friendly Environment and Glad I came. These are discussed alongside the literature, and it is proposed that whilst there is a substantial struggle involved in engagement with a RC, likely related to mental health and social factors, the RC environment, peer support and support of the tutors helps students to overcome the impact of this.

Research limitations/implications - Due to the small sample size and exploratory stance of this study, additional research into the complexities around engagement with RCs is strongly recommended. Only students who had attended at least one RC course chose to participate in this study, therefore an underresearched population of non-attendees may provide a valuable contribution to further understanding.

Originality/value - This is one of the first studies to qualitatively explore factors which may support, or hinder, initial and ongoing engagement with a RC. It is proposed that a greater understanding of these important issues could be used to increase RC accessibility and inclusion.

Keywords - Mental Health, Recovery, Recovery College, Co-production

Paper type - Research paper

Introduction

Recovery Colleges (RCs), as proposed by Perkins et al. (2012) are part of a shift to recovery focused organisational change in mental health services: A central focus on education and peer support aims to develop people's strengths in overcoming mental health difficulties. In light of this, RCs offer codeveloped and co-facilitated psychoeducational workshops. This operates on college principles, 
whereby service users, carers and staff members self-enrol to become 'students', and select courses from a prospectus.

Although the need for RC outcomes to be defined remains pivotal to development (Meddings et al. 2015b; McGregor et al. 2016), a collection of studies have highlighted the benefits of RC attendance for students and the organisation in which they are located (Zabel et al., 2016); with Meddings et al. (2015b) concluding that attendance at the RC has consistently been found to be useful, and help people progress towards their recovery goals. However, as noted by McGregor et al. (2014), the crucial elements of RCs need to be further explored.

The emphasis on co-production and peer support within RCs is, arguably, the most widely noted component of relevant academic discussion. Meddings et al. (2014) found that peer trainers offered hope and inspiration to students, and the collaboration between 'professional' and 'lived' experience has consistently been reported to be highly valued (Meddings et al., 2014a; Meddings et al., 2015; Newman-Taylor et al., 2016; Zabel et al., 2016), in addition to tutors personal values, empathy and knowledge (Meddings et al., 2014; Zabel et al., 2016). Research has also highlighted the importance of the RC learning environment; such as offering a safe, supportive and nonjudgemental space (Zabel et al., 2016; Zucchelli and Skinner, 2013), practical exercises (Zabel et al., 2016), adding structure to the day (Meddings et al., 2014; Zabel et al., 2016), offering space to socialise, and the ability to learn new skills (Meddings et al., 2014b). However, whilst there is satisfactory research into students' experiences whilst attending a RC, there has been little exploration into the initial motivations that may support, or hinder, this attendance.

Dunn et al. (2016) proposed that motivation, psychological wellbeing, physical illness and lack of communication were all factors that reduced engagement, in their small-sample study of nonattendees. Additionally, Zabel et al. (2016) suggested that a person's stage of recovery was also a potential barrier to engagement. Motivations for attendance and continued engagement however, have yet to be substantially explored within this setting. It has been proposed that focused research within this area can provide an additional framework for RCs to promote inclusion and engagement within a setting that is suggested to be highly beneficial to both service users and the organisation in which it operates (Zabel et al. 2016). In a contrary view, radical service users, survivors, and refusers of services can be critical of aspects of the recovery concept, notably a perceived unhelpful interrelationship with neoliberal policies linking self-reliance with austerity inspired welfare cuts (see RiTB https://recoveryinthebin.org/recovery-in-the-bin-19-principless/). These and other social policy critics also question whether the user-inspired notion of recovery has been diluted and co-opted by a more narrow bio-psychiatry (Harper \& Speed 2014, Pilgrim \& McRanie 2013). Regardless of the 
This study therefore aimed to explore students' motivations for enrolment and attendance with RCs, factors that may support or facilitate their learning within this setting, and barriers to attendance. As literature remains in its infancy stages, a qualitative approach was used to explore students' perceptions. Interviewees were recruited when students first enrolled with the RC, to promote inclusion of students who did not attend any courses, however interviews took place three months (one college term) after enrolment, once students were able to attend and engage with the RC programme.

\section{Approach}

A working group of seven individuals who had previously attended RC courses collaborated with the research team to develop the research aims, design and procedures. It was agreed that one-to-one semi-structured interviews would be most appropriate, ethically and practically, to discuss personal motivations for attendance alongside barriers that may have hindered this. It was also noted that a depth focus in this preliminary study could then shape wider analysis to ensure that areas for further research originate with RC participants themselves.

\section{Methods}

All new enrolments at a RC in the North West were invited to participate between September and October 2016. The RC's inclusion criteria were adopted, thus participants were over 17 years of age and using mental health services. This research design did not include staff members or carers. The study was promoted by RC staff and advertised using flyers; if students were interested in taking part they were offered a research pack, including an information sheet, consent form, and interview themes, and details were passed to the research team with their consent. A total of 89 individuals met the inclusion criteria during the study's recruitment period. 27 of these students requested an information pack and 11 consented to take part in the research. Three months following enrolment participants were invited to complete a semi-structured interview. Four participants opted to take part, all of whom identified as male. The average age of participants was 42 years $(S D, 12.4)$. Whilst this sample size is admittedly small and implies a limitation of the study, a commitment to in-depth interviewing to a certain extent redeems 
this. We feel that despite the small sample the findings are sufficiently interesting and original to justify publication and discussion.

All interviews took place at the participants local RC, with an equal split between two RC sites in the North West, and lasted between 20 and 50 minutes. Semi-structured themes included things that helped and/or hindered attendance at the RC, things that helped or hindered learning within courses, and if attendance at the college affected their mental health in any way. Interviews were audio-recorded.

\section{Data Analysis}

All interviews were transcribed verbatim and analysed with contribution from wider research team using thematic analysis (Ritchie et al. 2014), via cyclical reading and re-reading of the text. Analysis was facilitated and themes were organised using NVivo software.

\section{Ethical Considerations}

Ethical opinion was obtained from the NRES Committee North West (16/NW/0580), Health Research Authority, Research and Development locality team and University of Central Lancashire Ethics Committee. Information sheets were provided when participants first enrolled onto the study, when invited to interview and directly prior to the interview process, ensuring informed consent was obtained. Standard processes were followed for data security and confidentiality and clinical judgement used to promote the emotional wellbeing of participants during all research stages. A Public Patient Involvement group was also involved in the research design and structure.

\section{Findings}

The analysis identified four broad themes: making the effort; being "too unwell"; friendly environment; and glad I came. These are summarised below and illuminated with selected quotations from the data.

\section{Making the effort}

This theme relates to how attendance at the recovery college often represented a substantial effort for participants. On occasion, other social issues exacted a toll on individuals' resources such that 
they had little energy left to attend. More typically, students demonstrated commitment to attend and overcome barriers, and this in itself was indicative of success and a sense of recovery.

All participants interviewed had attended one or more courses at the RC. Motivations for attendance included curiosity, socialisation and wanting to learn; participants noted how they enrolled onto courses that they felt would "help" and "do [them] the most good".

Two participants did not attend courses that they were enrolled on, with both stating that this was related to housing problems. One participant had arranged to re-enrol onto the course once they had moved, with the other stating:

I didn't attend one course. Only because, erm, I ended up in a bit of a mess really [..] I wasn't really settled where I lived, and I was in the process of trying to move, and just, not quite on form really.

Some participants discussed how they "forced" themselves to attend courses, stating "I really didn't want to go yesterday, and I sort of like, had to give myself a kick up the arse and say, come on I better go." This idea also links with the notion that participants generally viewed attendance in itself as a part of the 'mental health recovery' process, for example:

I wouldn't have gone out; if I hadn't had been on them I probably wouldn't come out. And I, I look at my time, and I've, I've come on them all. Erm, so I mean that's something in itself, isn't it. [...] Even though it was hard to come out, l've still gotta come out. I've still gotta tryna keep on coming out, you know.

All participants stated that they would like to attend courses in the future, with one stating "I can only show my recommendation by wanting to come back as soon as I can".

\section{Being "Too unwell"}

This theme illustrates the struggle to learn in face of prevailing mental health difficulties. This was a matter of degree for different people, but in the extreme the impact of negative experiences, such as low mood, interacted complexly with motivation and self-efficacy to the detriment of learning. That said, these individuals nevertheless stuck with the course and attempted to struggle through. Participants noted factors such as physical disabilities, anxiety and mental health difficulties to have a negative impact on their learning within this setting. For example, one participant suggested that 
"the course would have less effect with somebody like me, than somebody who's got a lighter form of depression, which is more reasonably developed" and another participant stated:

They don't work because of how I feel, do you know what I mean, because of how I feel inside. I hate getting up every day feeling depressed and stuff. And the coping techniques are like, it's almost like too late in time.

Participant's generally had negative view of self-efficiency, with perceptions that their difficulties were "too severe" for any effective support. Nonetheless, participants continued to attend courses, despite these beliefs, with one participant stating that although "I wasn't very good at the creative class", "I know I'd go back for it, yeah, you know, and hopefully l'll be a bit more creative" and another proposing that "maybe it's too soon. Maybe l'll look back on them courses and they'll give me a little bit, erm, to free my anxiety, you know ... Because things like that do work afterwards, don't they."

\section{Friendly Environment}

Appreciation of the tutors and dynamics of the course were discussed as having a positive effect on participant's experiences and learning. Such relational aspects of the experience attest to a more social concept of mental distress, but interestingly, this extended to developing down to earth comprehension of fairly complicated bio-psychological processes. Conversely, too much selfdisclosure amongst peers appeared for some to adversely affect their appreciation.

Participants discussed the group dynamics and physical environment of the RC as being "friendly" and supportive, with a particular emphasis on the tutors, such as "I think [name of tutor] is great, really good tutor". When discussing what they had learnt, participants specified content that they had personally identified with, for example:

It's my Amygdala in the back on the brain thing that stuck with me, in my case. Because that's where I think I am, in fight or flight all the time.

It was suggested that the course content was "common sense" and "it was more the style of delivery than the fact that they were delivering new information". This practical method of delivery was relayed by participants as a positive, with one person also noting that they "got more out of the practical exercises in mindfulness sitting here in a group, rather than doing it on a one to one basis or being sat at home to do it." However, some participants also noted how listening to other 
people's difficulties could have a negative effect on their experience, suggesting limitations, for them, of the desirability of peer support:

I think because people do instinctively digress about their own condition, and that can be boring and, at times annoyingly boring [...] I mean the interaction was good, erm, and it's just, it could go too far.

\section{Glad I came}

This theme outlines the appreciative comments that were expressed by participants, and how they believed attendance at the RC has a positive effect on their mental health in terms of presenting difficulties and management plans. Participants expressed an appreciation for the RC and courses attended.

Participants noted how attendance at the college temporarily reduced their mental health symptoms; one stated that the course gave them "a bit of breathing space", with another discussing how they felt their anxiety reduced through the teaching time, and "relaxed [them] a little bit".

Positive comments about the RC, such as “it's a good gesture that these courses are on [...] I thought they were good" and "I'm glad I went on [the course]", were echoed across interviews. Additionally, participants noted that "there weren't any [courses] that I didn't find useful at all. They were all, I'm glad I came to them all".

\section{Discussion}

During their research into non-engagement with RCs, Dunn et al., (2016) identified motivation, psychological wellbeing and physical illness as barriers to attendance. Likewise, anxiety, mental health difficulties and physical illness were also identified as aspects which may reduce attendance within this analysis, with these factors additionally being noted to hinder learning within a course. Whilst participants discussed practical support that overcame physical difficulties, the focus on being 'too unwell' to get the most out of courses was notable across analysis. Although this concept has been proposed by Zabel et al. (2016) as a barrier to RC engagement, the complexities of how perceptions of mental health influence engagement have been further identified within this study. For example, despite expressing that their difficulties were "too severe" for effective support, participants continued to engage, displaying elements of hope that these difficulties would, in fact, subside, and viewed attendance in itself as part of their recovery. Further, participants discussed 
how their personal motivations could facilitate, or hinder, engagement with the RC. The idea that participants "forced" themselves to attend RC courses suggests that additional psychological factors may influence engagement and attendance. Perceptions surrounding mental health, and the psychological processes that may support or hinder students' personal commitment to attend, are therefore likely to have a major effect on engagement with RCs, both positively and negatively, and thus require focused attention and research.

Participants stated that they felt the RC environment was safe and discussed how the delivery of courses supported their learning. These findings have previously been outlined in literature (Meddings et al., 2015a; Zambel, et al., 2016; Zucchelli and Skinner, 2013) as being valued by RC students, and thus are likely to contribute to continued engagement and attendance. Participants also reflected on supportive group dynamics enhancing their learning, as previously noted by Meddings et al. (2104), however they also recognised the negatives of "too much" self-disclosure. Furthermore, although previous research has also highlighted the importance of learning from other students in RCs (Meddings et al., 2014; Meddings et al., 2015a), participants in this study conclusively agreed that they felt their learning mainly came from the tutors themselves. There is a possibility that these findings may be related to all tutors at the RC studied also having lived experience of mental health difficulties - thus the benefits of peer support outlined in literature may come directly from the tutors, without the risk of 'over-sharing' which has been associated with student peers - however this would require further investigation before any tangible conclusions can be drawn. Nonetheless, tutors' personal values have been previously identified by RC students as having a significant effect on their learning (Meddings et al., 204b; Zabel et al., 2016) which has been echoed in this analysis.

The recruitment of all students who enrol with a RC, inclusive of attendees and non-attendees, had the potential to offer an alternate narrative of RC's when compared to research that focuses on students who have attended multiple courses. However, as only students who attended one or more course consented to take part in this research, it is likely that an under-researched population of individuals who show an interest in engagement, but are potentially unable to overcome barriers to attendance, remains. It is possible that the relatively low number of participants in this research also reflects the struggle involved in $\mathrm{RC}$ attendance; if motivations such as being a friendly, group environment, where there is peer support and opportunity to learn, contribute toward overcoming the struggles associated with attendance then it is understandable that many students did not overcome these to attend an interview whereby few of the above were offered. This could suggest that this research only explored perceptions of highly motivated students, or those adept at 


\section{Conclusion}

These findings suggest that there is a substantial struggle involved in engagement with a RC, likely related to subjective mental health and social factors, however the RC environment, peer support and support of the tutors helps students to overcome the impact of this. Subjective experiences of mental health difficulties are suggested to influence engagement in both positive and negative ways, and focused research in this area is thus strongly recommended. These and future research findings in the field deserve an ongoing deliberative discussion that is cognisant of wider socio-political critique. This is necessary if the increasing focus on recovery as an organising principle for mental health care services is to transcend narrower bio-psychiatric co-option and challenge the powerful constraints of neoliberal austerity policies in the lives of contemporary mental health service users.

struggling to overcome barriers. Thus, additional data collection techniques should make use of the proposed factors that increase engagement alongside flexible and adaptive methods to increase accessibility to an under-researched population, and continue to explore factors that may influence their engagement. Awareness of these could further support continued RC development and accessibility.

In the light of more critical commentaries on recovery practices, it may very well be the case that 'refuseniks' are unsurprisingly absent from the student roll and hence among the interviewees here. The affinities for bio-psychological understandings and language may to some extent be explicable in these terms, or simply reflect the dominant socialisation processes within standard services. Conversely, appreciation for relational and peer supportive aspects of experiencing the recovery college may be more in tune with foundational recovery principles and hold promise for a greater emphasis on social models of distress going forward.

Finally, it is worth noting that although the research aims were to focus on factors involved in engagement with a RC, thematic analysis outlined general appreciation for the RC as a whole. This is consistent with previous literature and continues to support Meddings et al. (2015b) proposal that $\mathrm{RC}^{\prime} \mathrm{s}$ are useful for supporting people with mental health difficulties in their recovery. Whilst the findings proposed require additional support from larger, and potentially more inclusive, samples, this research has started to identify the complexities that may be involved in RC engagement. It is proposed that RCs offer time and resources to explicitly discuss students' practical and personal barriers to attendance and engagement, and individualised support plans subsequently offered to support them to attend something that supports mental health recovery, and offers "a bit of breathing space". 
The views expressed are those of the author(s) and not necessarily those of the NHS, the NIHR or the Department or Health.

\section{References}

Creswell, J.W. and Clarke, V.L (2011), Designing and Conducting Mixed Methods Research, Los Angeles: Sage. Second Edition.

Dunn, E.A., Chow, J., Meddings, S. and Haycock, L.J. (2016), "Barriers to attendance at Recovery Colleges", Mental Health and Social Inclusion, 20, (4), pp. 238-246.

Harper, D. and Speed, E. (2014) Uncovering recovery: The resistible rise of recovery and resilience. In De-Medicalizing Misery II (pp. 40-57). Palgrave Macmillan UK.

McGregor, J., Brophy, L., Hardy, D., Hoban, D., Meddings, S., Repper, J., Rinaldi, M., Roeg, W., Shepherd, G., Slade, M., Smelson, D and Stergiopoulos, V. on behalf of RCICoP Group (2016) Proceedings of June 2015 Meeting Recovery Colleges International Community of Practice (RCICoP)

McGregor, J., Repper, J. and Brown, H. (2014), "'The college is so different from anything I have done" A study of the characteristics of Nottingham Recovery College", Journal of Mental Health Education Training and Practice, 9, (1), pp. 3-15.

Meddings, S., Campbell, E., Guglietti, S., Lambe, H., Locks, L., Byrne, D. and Whittington, A.. (2015a), "From Service User to Student - The Benefits of Recovery Colleges", Clinical Psychology Forum, 268, 32-37.

Meddings, S., Guglietti, S., Lambe, H. and Byrne, D. (2014), "Student perspectives: recovery college experience", Mental health and Social Inclusion, 18, (3), pp. 142-150.

Meddings, S., McGregor, J., Roeg, W. and Shepherd, G. (2015b), "Recovery colleges: quality and outcomes", Mental Health and Social Inclusion, 19, (4), pp. 212-221.

Newman-Taylor, K., Stone, N., Valentine, P., Hooks, Z. and Zault, K. (2016), “The Recovery College: A unique service approach and qualitative evaluation", Psychiatric Rehabilitation Journal, 39, (2), pp. 198-190.

Perkins, R., Repper, J., Rinaldi, M. and Brown ,H. (2012), Recovery Colleges, London: Centre for Mental Health.

Pilgrim, D. and McCranie, A. (2013) Recovery and mental health: A critical sociological account. Basingstoke: Palgrave Macmillan.

Richie, J., Lewis, J., McNaughton-Nicholls, C. and Ormston, R. (2014), Qualitative Research Practice: A guide for social science students and researchers, SAGE: London. 
Zabel, E., Donegan, G., Lawrence, K. and French, P. (2016), "Exploring the impact of the recovery academy: a qualitative study of Recovery College experiences", Journal of Mental Health Training, Education and Practice, 11, (3), pp. 162-171.

Zucchelli, F.A. and Skinner, S. (2013), “Central and North West London NHS Foundation Trust's (CNWL) Recovery College: the story so far ...", Mental Health and Social Inclusion, 14, (4), pp. 183-189. 